
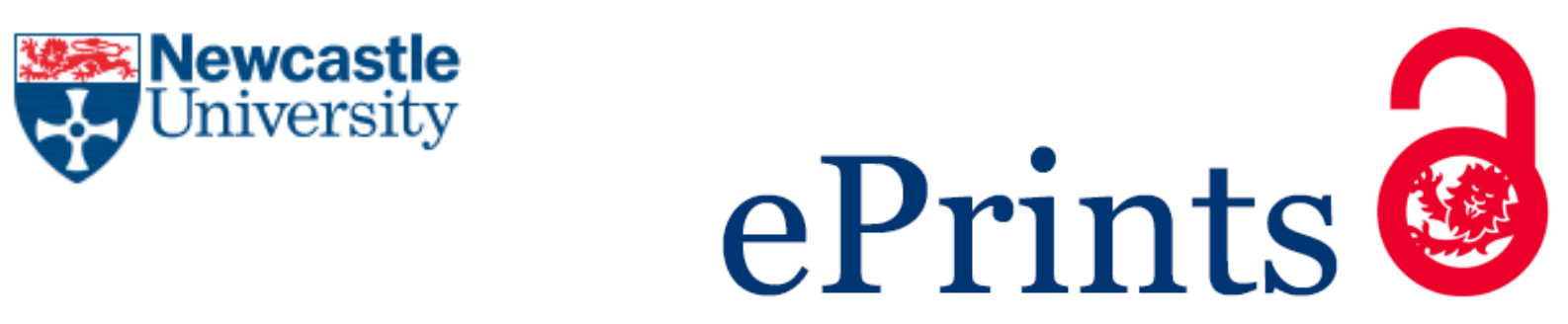

Han Z, Sani B, Mrozik W, Obst M, Beckingham B, Karapanagioti HK, Werner D. Magnetite Impregnation Effects on the Sorbent Properties of Activated Carbons and Biochars. Water Research 2015, 70(1), 394-403.

\title{
Copyright:
}

"CIWA Publishing 2015. The definitive peer-reviewed and edited version of this article is published in Water Research, 70(1), 394-403, 2015 http://dx.doi.org/10.1016/i.watres.2014.12.016 and is available at www.iwapublishing.com."

DOI link to article:

http://dx.doi.org/10.1016/j.watres.2014.12.016

Date deposited:

$18 / 09 / 2015$

Embargo release date:

17 December 2015

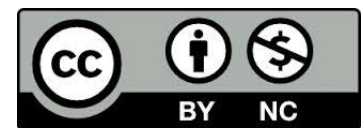

This work is licensed under a Creative Commons Attribution-NonCommercial 3.0 Unported License 


\section{Magnetite Impregnation Effects on the Sorbent Properties of Activated}

\section{Carbons and Biochars}

Zhantao Han ${ }^{\mathrm{a}, \mathrm{b}, \mathrm{c}}$, Badruddeen Sani ${ }^{\mathrm{a}}$, Wojciech Mrozik ${ }^{\mathrm{a}, \mathrm{d}}$, Martin Obst ${ }^{\mathrm{e}}$, Barbara Beckingham $^{\mathrm{e}, \mathrm{f}}$, Hrissi K. Karapanagioti ${ }^{\mathrm{g}}$ and David Werner ${ }^{\mathrm{a}, *}$

${ }^{a}$ School of Civil Engineering and Geosciences, Newcastle University, Newcastle upon Tyne, NE1 7RU, England, United Kingdom

${ }^{\mathrm{b}}$ Institute of Hydrogeology and Environmental Geology, Chinese Academy of Geological Sciences, Shijiazhuang, 050061, China

${ }^{\mathrm{c}}$ Hebei Key Laboratory of Groundwater Remediation, Shijiazhuang, 050061, China

${ }^{\mathrm{d}}$ Department of Inorganic Chemistry, Medical University of Gdańsk, 80-210 Gdańsk, Poland

e Department of Geosciences, Center for Applied Geoscience, University of Tübingen, Hölderlinstr. 12, 72074 Tübingen, Germany

${ }^{\mathrm{f}}$ Department of Geology and Environmental Geosciences, College of Charleston, Charleston, SC 29401, USA

g Department of Chemistry, University of Patras, 26504, Patras, Greece

* Corresponding author phone: 0044191222 5099; fax: 00441912226502

E-mail: david.werner@ncl.ac.uk.

\section{Abstract}

This paper discusses the sorbent properties of magnetic activated carbons and biochars produced by wet impregnation with iron oxides. The sorbents had magnetic susceptibilities consistent with theoretical predictions for carbon-magnetite composites. The high BET surface areas of the activated carbons were preserved in the synthesis, and enhanced for one low surface area biochar by dissolving carbonates. Magnetization decreased the point of zero 
charge. Organic compound sorption correlated strongly with BET surface areas for the pristine and magnetized materials, while metal cation sorption did not show such a correlation. Strong sorption of the hydrophobic organic contaminant phenanthrene to the activated carbon or biochar surfaces was maintained following magnetite impregnation, while phenol sorption was diminished, probably due to enhanced carbon oxidation. Copper, zinc and lead sorption to the activated carbons and biochars was unchanged or slightly enhanced by the magnetization, and iron oxides also contributed to the composite metal sorption capacity. While a magnetic biochar with $219 \pm 3.7 \mathrm{~m}^{2} / \mathrm{g}$ surface area nearly reached the very strong organic pollutant binding capacity of the two magnetic activated carbons, a magnetic biochar with $68 \pm 2.8 \mathrm{~m}^{2} / \mathrm{g}$ surface area was the best metal sorbent. Magnetic biochars thus hold promise as more sustainable alternatives to coal-derived magnetic activated carbons.

\section{Highlights}

- We compared the adsorption of phenanthrene, phenol and heavy metal ions by magnetic activated carbon and magnetic biochar.

- Strong sorption of phenanthrene to the activated carbon or biochar surfaces was maintained following magnetite impregnation.

- Phenol sorption was diminished by magnetite impregnation, probably due to enhanced carbon oxidation.

- A high surface area biochar nearly reach the strong organic pollutant sorption capacity of activated carbon. 


\section{Introduction}

Activated carbon is one of the most widely used sorbent materials for the purification of water (Sontheimer, et al., 1988), air (Cheremisinoff 2002), soil (Sarah E. Hale, et al., 2012a, Vasilyeva, et al., 2001) and sediment matrices (Cho, et al., 2012, Ghosh, et al., 2011, Zimmerman, et al., 2004). While powdered activated carbon has better sorption kinetic properties than granular activated carbon (Ahn, et al., 2005), the separation of powdered activated carbon from cleaned environmental matrices is challenging. This is especially true for the novel soil and sediment remediation applications (Ghosh, et al., 2011), where powdered activated carbon recovery from slurries of soil or sediment particles cannot be achieved with traditional coagulation/flocculation/clarification processes. Magnetic activated carbon (Faulconer, et al., 2012, Kakavandi, et al., 2013, Mohan, et al., 2011, Ngarmkam, et al., 2011, Oliveira, et al., 2002, Yang, et al., 2008) or magnetic biochar (Chen, et al., 2011, Zhang, et al., 2007) may provide an alternative route to the recovery of pollutant-loaded sorbents from cleaned environmental matrices. Magnetic activated carbon has been effectively used for organic and inorganic pollutants removal from wastewater (Castro, et al., 2009, Oliveira, et al., 2002) and also in the mining industry (Rossier, et al., 2009).

Environmental impact analysis shows that locally produced biochar provides a more sustainable alternative to the use of coal-derived activated carbon (Sparrevik, et al., 2011), but biochar will not necessarily have equivalent sorption properties (Sarah E. Hale, et al., 2012b). The relative performance of magnetic activated carbon and magnetic biochar is therefore of great interest. Magnetic activated carbons and biochars have higher production costs, and may have changed sorbent properties, in comparison with the unaltered activated carbons and biochars. Better understanding of potential trade-offs between the desirable attribute of magnetism and its side-effects on the pollutant binding capacity of magnetic sorbent materials is also required to properly assess the economic sense and technical feasibility of various treatment applications. The aim of this study was therefore a detailed characterization of 
magnetite impregnation effects on the sorbent properties of two types of commercial activated carbons (one produced from coal and one produced from coconut shells, which may be also described as an 'activated biochar') and two types of commercial biochars (both made from mixed wood at $500^{\circ} \mathrm{C}$, one produced in Romania, and one produced locally in the $\mathrm{UK}$ and marketed as sustainable and organic). A series of adsorption experiments were conducted to compare the adsorption ability of these two activated carbons and two biochars with and without magnetite impregnation for different pollutant classes comprising hydrophobic organic contaminants (phenanthrene), more hydrophilic organic contaminants (phenol), and positively charged bivalent heavy metal pollutants $\left(\mathrm{Pb}^{2+}, \mathrm{Cu}^{2+}\right.$, and $\left.\mathrm{Zn}^{2+}\right)$ which may have electrostatic interactions with negative surface charges of the sorbents. To the best of our knowledge the present study offers the first comparison of magnetite impregnated activated carbons and biochars synthesized with the same procedures.

\section{Materials and Methods}

\subsection{Materials}

Two kinds of commercial activated carbon were investigated, one produced from Coconut shells by Norit, and one produced from anthracite coal by Calgon (Calgon Filtrasorb 400) and obtained from Chemviron (Lancashire, United Kingdom). Two kinds of commercial biochar were obtained from Romchar (Harghita, Romania), and Oxford Biochar Ltd. (Dorset, UK), respectively. According to the manufacturers, both biochars were made from mixed wood chips with a maximum pyrolysis temperature of $500^{\circ} \mathrm{C}$, and the UK biochar was described by the producer as sustainable and organic. The sorbents were labelled CocoAC, CoalAC, Bio, and OrgBio, respectively. CocoAC, CoalAC, Bio and OrgBio were ground with a ceramic mortar to realize a $<64 \mu \mathrm{m}$ size distribution.

Phenanthrene stock solution $(5000 \mu \mathrm{g} / \mathrm{mL}$ in methanol) was bought from Supelco (Bellefonte, PA, USA). Metal salts $\left(\mathrm{CuCl}_{2} \cdot 2 \mathrm{H}_{2} \mathrm{O}\right.$ and $\left.\mathrm{ZnCl}_{2}\right)$ were obtained from BDH Laboratory 
Supplies (Poole, England) and $\mathrm{Pb}\left(\mathrm{NO}_{3}\right)_{2}$ from Merck (Darmstadt, Germany). Iron salt $\mathrm{FeSO}_{4} \cdot 7 \mathrm{H}_{2} \mathrm{O}$ was obtained from BDH Laboratory Supplies (Poole, England) and $\mathrm{FeCl}_{3} \cdot 6 \mathrm{H}_{2} \mathrm{O}$ was obtained from VWR (Lutterworth, UK). Aqueous phenol solution (30 g/L) was obtained from VWR (Lutterworth, UK). Ethanol with $>99.8 \%$ purity was obtained from VWR

(Lutterworth, UK). A phenanthrene and a deuterated phenanthrene calibration standard in methanol were obtained from Supelco (Bellefonte, PA, USA), Hexane (for pesticide residue analysis) and acetone (for HPLC analysis) were bought from Sigma-Aldrich (St. Louis, MO, USA).

\subsection{Preparation of magnetite impregnated $\mathrm{AC}$ and biochar}

Magnetic activated carbon and biochar were prepared by a chemical precipitation technique as presented in Supporting Information. This method is based on a technique used in previous studies (Castro, et al., 2009, Oliveira, et al., 2002), but with a few modifications. Briefly, 2.5 g AC or BC, $1.83 \mathrm{~g} \mathrm{FeSO}_{4} \cdot 7 \mathrm{H}_{2} \mathrm{O}$ and $3.33 \mathrm{~g} \mathrm{FeCl}_{3} \bullet 6 \mathrm{H}_{2} \mathrm{O}$, and $100 \mathrm{~mL}$ de-ionized water were combined in a beaker. The mixtures were stirred and heated to $65^{\circ} \mathrm{C}$ and then cooled by stirring to below $40^{\circ} \mathrm{C} .5 \mathrm{M} \mathrm{NaOH}$ solution was added drop wise to raise the $\mathrm{pH}$ to $10-11$ and precipitate the iron hydroxides. The mixtures were stirred for 1 hour and then rested overnight. The supernatants were removed, and the precipitates were washed and rinsed with de-ionized water onto a coffee filter, then rinsed with ethanol and dried at $80^{\circ} \mathrm{C}$ in an oven. The magnetic carbon materials were labelled as MagCocoAC, MagCoalAC, MagBio, and MagOrgBio, respectively.

\subsection{Sorbent characterization}

The size distributions were measured by a laser diffraction method using a Malvern MasterSizer 2000 (Malvern, UK) which can measure particle size between $20 \mathrm{~nm}$ and $2 \mathrm{~mm}$. The specific surface area (SSA), pore volume, and average pore size of the samples were determined by gas $\left(\mathrm{N}_{2}\right)$ adsorption/desorption with the Micromeritics TriStar 3000 Analyzer 
system using the Brunauer, Emmett, and Teller (BET) equation. Isotherms with 30 adsorption and 20 desorption points were conducted at liquid nitrogen temperature $(77 \mathrm{~K})$. To determine the open surface area, relative pressures above 0.3 were used since at this pressure all the micropores should be filled and only sorption to open surface area should be occurring(de Boer, et al., 1966).

To determine the point of zero charge of carbon surfaces, $5-7$ bottles of inert electrolyte $0.1 \mathrm{M}$ $\mathrm{NaNO}_{3}$ (pH 6.5) were prepared for each material according to a mass titration method (Reymond and Kolenda, 1999). The volume of electrolyte in each bottle was $20 \mathrm{~mL}$ and different amounts of each carbon were added. The suspension $\mathrm{pH}$ was measured after one day with a Sentek electrode purchased from Metrohm Ion Analysis.

The mineral composition of the pristine and magnetic carbons was characterized by X-ray powder diffraction (XRD). The XRD instrument is a PANalytical X'Pert Pro MPD, powered by a Philips PW3040/60 X-ray generator and fitted with an X'Celerator detector. Continuous scan XRD data were collected at diffraction angles between $10^{\circ}$ and $90^{\circ}$ operating at $40 \mathrm{~mA}$ and $40 \mathrm{kV}$.

A Varian 800 FT-IR spectrometer system produces spectra between $4000 \mathrm{~cm}^{-1}$ and $400 \mathrm{~cm}^{-1}$ using a Pike Technologies diamond crystal plate ATR unit and was used for analysing the transmittance of the pristine and magnetic carbons in infrared wavelengths.

The particle shapes and surface element distribution were measured by a Scanning Electron Microscope equipped with an Everhart Thornley secondary electron detector, a 4 quadrant backscattered electron detector, and an EDX detector (SEM, Leo 1450 VP, Oxford INCA Energy 200 Premium Si (Li) SATW-Detector). The acceleration voltage used was $17 \mathrm{kV}$. The samples were prepared by dry deposition of the carbon particles on conductive, sticky carbon pads, and then coated with $8 \mathrm{~nm}$ carbon using a BAL-TEC SCD 005 sputter coater with the carbon evaporation unit CEA 035. The SEM-EDX maps were normalized to the highest intensity pixels, and analyzed by ScatterJ (V0.6) (Zeitvogel, et al., 2014) used for 2D plots of 
element distribution and correlation of different elements.

Magnetic susceptibility was measured at room temperature using a magnetic susceptibility meter (AGICO Kappabridge MFK1 series). Bulk density was measured by tapping about $2 \mathrm{~g}$ of magnetic ACs and biochars in a $10 \mathrm{~mL}$ glass graduated cylinder readable to $0.2 \mathrm{~mL}$ until the volume did not change appreciably. Material density of magnetic AC and biochars was determined by pycnometer (Accupyc 1330, Micromeritics).

\subsection{Sorption of phenanthrene from water}

Adsorption isotherms of phenanthrene on CoalAC and MagCoalAC were obtained using a batch equilibration technique at $20 \pm 1{ }^{\circ} \mathrm{C}$, for which $3 \mathrm{mg}$ CoalAC or MagCoalAC were combined with $40 \mathrm{~mL}$ of background solution containing $100 \mathrm{mg} / \mathrm{L} \mathrm{NaN} 3$ as biocide in $40 \mathrm{~mL}$ amber glass vials with Teflon screw caps obtained from VWR (Lutterworth, UK). A hexane: acetone (80:20) pre-extracted polyethylene (PE) sampler (300 mg, $26 \mu \mathrm{m}$ thick, produced from PE plastic bags obtained from VWR, Lutterworth, UK) was added to each vial to reliably monitor low aqueous phenanthrene concentrations (S. E. Hale and Werner, 2010). Different volumes of phenanthrene in methanol stock solution or diluted stock solution were injected to achieve aqueous phenanthrene concentrations spanning three orders of magnitude. The volume fraction of methanol in solution of each vial was less than 0.003 to avoid cosolvent effects. Duplicate controls were used for all phenanthrene concentration points with PE samplers, but without adsorbents. All the samples were shaken on a rotary shaker at 110 rpm for 30 days. Previous studies showed that the adsorption of phenanthrene on similar-sized activated carbon reached equilibrium within 30 days (S. E. Hale and Werner, 2010), whereas the equilibrium of PAHs between PE and water is established even faster (Adams, et al., 2007). After mixing, the PE samplers were collected, wiped cleaned with lab tissue and extracted twice for $24 \mathrm{~h}$ with $10 \mathrm{~mL}$ hexane: acetone 80:20 v:v solvent. According to a previous study, more than $99.9 \%$ of phenanthrene can be recovered by this extraction procedure (Choi, et al., 2013). The extractions were concentrated to approximately $1 \mathrm{~mL}$ 
under a gentle stream of ultra-pure grade nitrogen after a fixed amount of deuterated phenanthrene had been added as recovery standard. Phenanthrene was quantified without further sample clean-up by gas chromatography mass spectrometry performed on an Agilent 7890A GC split/split less injector $\left(280^{\circ} \mathrm{C}\right)$ linked to a Agilent 5975C MSD (electron voltage $70 \mathrm{eV}$, source temperature $230^{\circ} \mathrm{C}$, quad temperature $150^{\circ} \mathrm{C}$ multiplier voltage $1800 \mathrm{~V}$, interface temperature $310^{\circ} \mathrm{C}$ ). Data acquisition was performed in selected ion mode.

Sorbent-water distribution coefficients, $K_{D}$, values of phenanthrene on all the other sorbents were also obtained by the same procedure, but only at one initial spiked phenanthrene concentration. Different weights of carbon materials (3 mg CocoAC, MagCocoAC, Bio; 15 mg MagBio, 100 mg OrgBio, 200 mg MagOrgBio) were used to achieve similar final equilibrium aqueous phenanthrene concentrations, which were estimated based on a preliminary experiment using the same method with equal amounts of each adsorbent.

\subsection{Sorption of phenol from water}

Phenol sorption experiments were conducted in $60 \mathrm{~mL}$ amber glass vials with a Teflon-lined screw cap supplied by VWR (Lutterworth, UK) into which $50 \mathrm{mg}$ of each sorbent were added and then saturated with $39 \mathrm{~mL}$ autoclaved $0.01 \mathrm{M} \mathrm{CaCl}_{2}$ solution and allowed to stand overnight. The desired initial batch phenol concentrations $(5-100 \mathrm{mg} / \mathrm{L})$ were obtained by adding $1 \mathrm{~mL}$ of de-ionized water pre-diluted stock solution into the equilibrated $\mathrm{CaCl}_{2}$ sorbent mixture. Blank controls containing phenol solution without sorbent were run in parallel with the samples to check for phenol degradation. The vials were shaken on a constant temperature oscillator (KS 4000i by IKA) at $90 \mathrm{rpm}$ for 7 days at $20^{\circ} \mathrm{C}$. Duplicate batches were set up for all phenol concentrations. After shaking, the samples were filtered using a $25 \mathrm{~mm}$ syringe filter with a $0.45 \mu \mathrm{m}$ PTFE membrane obtained from VWR International (Lutterworth, UK). HighPerformance Liquid Chromatography (HPLC) was used to determine the amount of phenol remaining in the filtrate. The HPLC system (Shimadzu; Kyoto, Japan) consisted of an LC10AD VP pump, SIL-10A VP autosampler, SPD-10A VP UV detector, and SCL 10 A-VP 
controller unit. Data were acquired and processed by CLASS-VP V 5.032 software. The stationary phase was a Gemini-NX 150 x $4.6 \mathrm{~mm}, 5 \mu, \mathrm{C} 18,110$ E column (Phenomenex, USA). The mobile phase consisted of acetonitrile and water (50:50\% v/v), at an isocratic flow rate of $1 \mathrm{~mL} \mathrm{~min}{ }^{-1}$. The elution profiles were recorded at $254 \mathrm{~nm}$, and the injection volume was $10 \mu \mathrm{L}$.

\subsection{Sorption of bivalent metal cations from water}

Metal sorption experiments were conducted using $50 \mathrm{~mL}$ polyethylene plastic vials with screw cap, obtained from VWR (Lutterworth, UK), into which $50 \mathrm{mg}$ of the sorbent was added followed by $40 \mathrm{~mL}$ of the desired concentration $(0.01,0.04,0.08,0.16$ or $0.30 \mathrm{mM})$ of mixed metal salts solution. Mixed metal solution having the same molar concentrations of each metal was prepared from $\mathrm{Pb}\left(\mathrm{NO}_{3}\right)_{2}, \mathrm{CuCl}_{2} \cdot 2 \mathrm{H}_{2} \mathrm{O}$, and $\mathrm{ZnCl}_{2}$. The vials were immediately closed using the screw cap and set to shake on a constant temperature oscillator (70 rpm) for 7 days at $20^{\circ} \mathrm{C}$. A similar experiment was conducted using single metal solution having the same concentrations for the OrgBio and MagOrgBio sorbents. Metals solution containing no sorbent was run parallel with the samples as control. Samples were run in duplicates for each concentration and average values were reported. After shaking, the samples were filtered using a $0.45 \mu \mathrm{m}$ PTFE membrane syringe filter and the filtrate was analysed for residual individual metal concentration using a Varian Vista MPX axial ICPOES with CCD, operated according to standard methods for examination of water and wastewater. Metals were detected at several wavelengths and the readings averaged for each: $\mathrm{Cu}^{2+}(213.598,324.745$ and $327.395 \mathrm{~nm}) ; \mathrm{Pb}^{2+}(182.143,217.000$ and $220.353 \mathrm{~nm})$; and $\mathrm{Zn}^{2+}$ (202.548, 206.200 and $213.857 \mathrm{~nm})$. The amount of metal species adsorbed per unit weight of adsorbent was computed using the difference between concentrations measured in batches with sorbents and batches without sorbents, using a mass balance approach.

\subsection{Sorption isotherm models}

The Langmuir, Freundlich and Redlich-Peterson sorption isotherm models were considered 
for fitting multi-concentration point data. For all isotherm data, parameter fitting was done using linear transformations and nonlinear regressions as explained in Supporting Information.

The Langmuir model (Langmuir, 1916) is given as:

$$
Q_{e}=\frac{Q_{m} K_{L} C_{e}}{1+K_{L} C_{e}}
$$

Where the constants $Q_{m}$ and $K_{L}$ are, respectively, the maximum monolayer adsorption capacity $(\mathrm{mg} / \mathrm{kg}$ ) and Langmuir constant $(\mathrm{L} / \mathrm{mg})$, which is related to the energy of adsorption and increases as the strength of adsorption bond increases. $Q_{e}$ and $C_{e}$ are the constituent adsorbed per unit weight of carbon $(\mathrm{mg} / \mathrm{kg})$ and equilibrium aqueous phase concentration (mg/L), respectively.

The Freundlich model is expressed as:

$$
Q_{e}=K_{F} C_{e}^{\frac{1}{n}}
$$

Where the constant $1 / \mathrm{n}$ is a dimensionless value between 0 and 1 and is related to adsorption intensity while $K_{F}$ is related to adsorption capacity for a given adsorbent $(\mathrm{mg} / \mathrm{kg})(\mathrm{L} / \mathrm{mg})^{1 / \mathrm{n}}$ (Carter, et al., 1995).

The Redlich-Peterson (Redlich and Peterson, 1959) model is expressed as:

$$
Q_{e}=\frac{K_{R} C_{e}}{1+A_{R} C_{e}^{\beta}}
$$

Where the constants $K_{R}$ and $A_{R}$ are the Redlich-Peterson isotherm constants $(\mathrm{L} / \mathrm{kg})$ and $(\mathrm{L} / \mathrm{mg})^{\beta}$, respectively, while $\beta$ is an exponent that lies between 0 and 1.

\section{Results and discussion}

\subsection{Sorbent characterization}

The geometric mean particle sizes of ground CocoAC, CoalAC, and Bio was 7.3-7.8 $\mu \mathrm{m}$, while OrgBio particle size was three times larger $(25.5 \mu \mathrm{m})$, but still in the range of powdered 
activated carbons (Table 1). The BET surface areas (Table 1) of the two pristine activated carbons were superior $\left(974-975 \mathrm{~m}^{2} / \mathrm{g}\right)$ to those of the two biochars $\left(261\right.$ and $6 \mathrm{~m}^{2} / \mathrm{g}$ for Bio and OrgBio, respectively), demonstrating the benefit of the activation. The difference in the BET surface areas of the two biochars was quite remarkable. The magnetizing process decreased the BET surface areas and micropore volumes of the activated carbons, but increased the surface area of OrgBio, and the pore volumes of Bio and OrgBio. The decrease of surface areas of the magnetite impregnated activated carbons was similar with that observed by previous studies (Castro, et al., 2009, Oliveira, et al., 2002), and can be explained by the pristine carbon material and iron oxide weight ratios in the composite materials. The surface area of iron oxides produced by this method is $66 \mathrm{~m}^{2} / \mathrm{g}$ according to Oliveira et al. (Oliveira, et al., 2002). For MagCocoAC and MagCoalAC, the measured surface areas were generally consistent with theoretical values calculated based on mass ratios (Table 1), which shows that the iron oxide impregnation didn't measurably decrease the surface area of the pristine sorbent materials. For MagBio and MagOrgBio, the measured surface areas $\left(219 \pm 3.7 \mathrm{~m}^{2} / \mathrm{g}\right.$ and $68 \pm 2.8 \mathrm{~m}^{2} / \mathrm{g}$, respectively) were higher than the calculated values $\left(189 \mathrm{~m}^{2} / \mathrm{g}\right.$ and 28 $\mathrm{m}^{2} / \mathrm{g}$ ). This increase may have resulted from the dissolution of calcite incorporated in the biochar pores, because calcite was detected by XRD in Bio and OrgBio, but not in MagBio and MagOrgBio (Fig.1), which may also explain the increased pore volumes of Bio and OrgBio. The dissolution of calcite is expected since $\mathrm{pH}$ was decreased to 1.5 while adding ferrous sulphate and ferric chloride into the solution during sorbent synthesis. For all the magnetic carbon materials, the specific open surface areas have been increased compare with their pristine form, this increase should come from the high specific open surface areas of the iron oxides.

The theoretical and measured mass magnetic susceptibility of the magnetic carbon materials are also compared in Table 1 . The theoretical mass magnetic susceptibility was calculated by assuming all the added iron precipitated as magnetite, and using a value for mass magnetic 
susceptibility of magnetite with particles sizes between 0.09 and $2000 \mu \mathrm{m}\left(6.0^{*} 10^{-4} \mathrm{~m}^{3} / \mathrm{kg}\right.$, (Dearing, 1999)) along with its mass fraction in the composites. The measured mass magnetic susceptibilities of iron oxides impregnated sorbents were broadly in line with these theoretical values. Deviations from the theoretical values may have resulted from the small particle sizes of magnetite formed in/on the carbonaceous sorbents or the formation of maghemite in the impregnation process. Magnetite with small particle sizes (0.012-0.069 $\mu \mathrm{m})$ has variable mass magnetic susceptibilities $\left(513-1116^{*} 10^{-6} \mathrm{~m}^{3} / \mathrm{kg}\right)$, and maghemite has weaker magnetic susceptibility than magnetite (Dearing, 1999). According to their XRD patterns (Fig.1), the main minerals deposited on the carbon were either magnetite or maghemite. Magnetite or maghemite have similar XRD patterns (Kim, et al., 2012) and are difficult to distinguish with this method. The absorbance of $\mathrm{FeO}$ bonds from magnetite or maghemite was also observed in the FTIR spectrum (Fig.2). This FeO absorbance was not from goethite (FeOOH) since goethite also has absorbance at 795 and $899 \mathrm{~cm}^{-1}$ (Castro, et al., 2009), which were not observed in our samples. These results were similar to a previous study using a similar magnetizing method (Oliveira, et al., 2002), and better than another previous study which produced mainly goethite (Castro, et al., 2009) which only has moderate magnetic susceptibility (Dearing, 1999).

The magnetizing process decreased the point of zero charge (PZC) of the carbon materials (Table 1). This decrease was likely caused by the surface coverage with magnetite or maghemite, since the point of zero charge of magnetite and maghemite is about 6.5 or somewhat higher (Lucas, et al., 2007, Milonjić, et al., 1983, Shen, et al., 1999), while all the pristine carbonaceous sorbents had a point of zero charge $>8.7$. The point of zero charge decrease might also derive from the oxidation of carbon surfaces from ferrous sulphate and ferric chloride acids added in the initial stage of the magnetizing process (Borah, et al., 2009), since a weak broad $\mathrm{OH}$ stretch absorbance at about $3400 \mathrm{~cm}^{-1}$ appeared to deepen slightly in the magnetic carbon spectra (Fig.2). 


\subsection{Pollutant sorption characterization}

304

\subsubsection{Phenanthrene and phenol sorption}

Phenanthrene sorbent-water distribution $\left(K_{D}\right)$ values of the pristine sorbents determined at a single concentration point in the 7-27 ng/L free aqueous concentration range are compiled in Table 2 and followed the order of CocoAC $\approx$ CoalAC $>$ Bio $>$ OrgBio, in accordance with their pore volumes and surface areas. For the impregnated sorbents, the $K_{D}$ values also followed the same order: MagCocoAC $\approx$ MagCoalAC > MagBio > MagOrgBio. The reduced activated carbon or biochar content (64\%) of these composite materials can readily explain the difference between pristine and impregnated sorbent materials. The $K_{D}$ values of the magnetic composites were between $58 \%$ and $66 \%$ of those of the pristine materials. This suggests that phenanthrene did not sorb significantly to the iron oxides, and impregnation with iron oxide minerals did not significantly change the phenanthrene affinity for the activated carbon or biochar surfaces in the composites. As illustrated in Fig.3(a), the sorption of phenanthrene on CoalAC and MagCoalAC was nonlinear and was fitted well by the Freundlich model with correlation coefficients $\left(\mathrm{R}^{2}\right)$ of 0.98 . When normalized by the activated carbon content, both the $\log K_{f}$ values of CoalAC and MagCoalAC (6.22 and 6.27) and the $1 / \mathrm{n}$ values ( 0.78 and 0.82 , respectively) were similar, indicating that the activated carbon matrix determined the phenanthrene adsorption as already discussed above. The sorption capacity and affinity of phenanthrene on CoalAC had similar values to the results of Walters and Luthy (Walters and Luthy, 1984), who used the same adsorbent, Calgon Filtrasorb 400.

Phenol sorption (Table 3) broadly followed the positive correlation with BET surface areas already observed for phenanthrene sorption (Table 2), and also reported in the literature (Dąbrowski, et al., 2005). While the decrease in the maximum phenol sorption capacity, $Q_{m}$, values of magnetite impregnated sorbents was in line with the $35.7 \%$ reduction, which could be simply explained by the reduced activated carbon or biochar content of the composite 
materials, the decrease in the phenol Langmuir $K_{L} \cdot Q_{m}$ values of magnetite impregnated sorbents was mostly much greater (Table 3). Apparently, activated carbon or biochar surface alterations during the acidic conditions of the magnetization procedure not only reduced the point of zero charge values (Table 1) and increased surface oxidation (Fig.2), but also negatively affected the phenol sorption at lower aqueous concentrations (Table 3, Fig.3(b)), which agrees with previous reports of phenol adsorption inhibition with increased oxidation of activated carbon surfaces (Dąbrowski, et al., 2005). Phenol sorption on CocoAC and MagCocoAC was fairly well described by the Freundlich model (Fig.3(b)), although the uptake of phenol on MagCocoAC was actually best fitted by the Langmuir model (Table S1 in Supporting Information). Phenol sorption to CocoAC and MagCocoAC was highly nonlinear (1/n values of 0.48 and 0.51 , respectively) with $\log K_{f}$ values of 5.01 and 4.37 , respectively. Previously reported Freundlich isotherm parameters for phenol sorption on Filtrasorb 300 activated carbon were a $\log K_{f}$ value of 4.7 and $1 / \mathrm{n}$ of 0.54 over a concentration range of 2-10 mg/L and at pH 3.9 (Dąbrowski, et al., 2005). In another study by Oliveira et al. (Oliveira, et al., 2002), an activated carbon iron oxide composite of ratio 3:1 was used in the sorption of phenol and an adsorption capacity of $1.17 \cdot 10^{5} \mathrm{mg} / \mathrm{kg}$ was reported. In this work, similar values of $(0.7-0.8) \cdot 10^{5} \mathrm{mg} / \mathrm{kg}$ were observed as the sorption capacities of MagCoalAC and MagCocoAC for phenol based on the Langmuir's sorption capacity factor $Q_{m}$ (Table 3), even though the ratio for carbon to iron oxide was lower at about 1.7:1.

\subsubsection{Zinc, copper, and lead sorption}

Metal sorption is not correlated with the BET surface areas, and the low surface area OrgBio had $Q_{m}$ and $K_{L}$ Langmuir sorption isotherm parameter values for $\mathrm{Pb}^{2+}$ and $\mathrm{Cu}^{2+}$ in the range of or better than the activated carbons (Table 4), which suggests that functional groups were more relevant than the carbon surface area for metal adsorption. The Langmuir model (Fig.4(a) and (b)) described the metal data better than the Freundlich model, indicating a maximum metal sorption capacity at high metal concentrations, which is consistent with the 
concept of metals interacting with a limited number of specific sorption sites.

Contrary to the organic pollutant observations, magnetite/maghemite impregnation did not consistently reduce bivalent metal sorption (Table 4 and Fig.4(a) and (b)). This can be explained by metal sorption to the iron minerals (Fig.4(c)), and/or by increased oxidation of activated carbon or biochar surfaces and reduced points of zero charge facilitating the adsorption of bivalent metals. The reported maximum $\mathrm{Cu}^{2+}$ sorption capacity of nano-scale $\mathrm{Fe}_{3} \mathrm{O}_{4}$ particles is for instance $8900 \mathrm{mg} / \mathrm{kg}$ at $\mathrm{pH} 5$ for $\mathrm{Cu}\left(\mathrm{NO}_{3}\right)_{2}$ solutions (Xue Song Wang, et al., 2011). In this study, the measured maximum $\mathrm{Cu}^{2+}$ sorption capacity on magnetite alone (Fig.4(c) and Table S2 in Supporting Information) was $1975 \mathrm{mg} / \mathrm{kg}$ as compared to 7314 $\mathrm{mg} / \mathrm{kg}$ for OrgBio, indicating that magnetite contributes to some extent to the $\mathrm{Cu}^{2+}$ sorption capacity of the MagOrgBio composites.

The solution $\mathrm{pH}$ values for all the metal sorption experiments are listed in Supporting Information (Tables S6 and S7). The equilibrium $\mathrm{pH}$ range for $\mathrm{Pb}^{2+}$ sorption was between 6.3 and 8.9 for OrgBio, and between 4.4 and 5.5 for MagOrgBio. The sorption of $\mathrm{Cu}^{2+}$ and $\mathrm{Zn}^{2+}$ on OrgBio and MagOrgBio was measured at $\mathrm{pH}$ values similar to those of the $\mathrm{Pb}^{2+}$ experiments. $\mathrm{Pb}^{2+}$ dominates the speciation of lead below water $\mathrm{pH} 6.2$, while $\mathrm{Pb}(\mathrm{OH})^{+}$is formed in the $\mathrm{pH}$ range between 6.2 and 10.8 , and $\mathrm{Cu}^{2+}$ dominates speciation of copper below water $\mathrm{pH}$ 6.6, while $\mathrm{Cu}(\mathrm{OH})^{+}$is formed in the $\mathrm{pH}$ range between 6.6 and 11 (Takeno, 2005). For zinc, $\mathrm{Zn}^{2+}$ dominates below water $\mathrm{pH} 7.5$ (Yuen-Hua Wang, et al., 2003), while $\mathrm{Zn}(\mathrm{OH})^{+}$ may form when $\mathrm{pH}$ is between 7.5 and 9.9 (Takeno, 2005). Hence, these heavy metals keep species with positive charge in solution during the sorption experiments to OrgBio and MagOrgBio.

For single metal solutions, the maximum sorption capacities of OrgBio and MagOrgBio expressed on a molar basis was highest for $\mathrm{Pb}^{2+}(0.24$ and 0.14 moles $/ \mathrm{kg})$ and comparable for $\mathrm{Cu}^{2+}(0.12$ and 0.12 moles $/ \mathrm{kg})$, and $\mathrm{Zn}^{2+}(0.12$ and 0.07 moles $/ \mathrm{kg})$, respectively. However, in 
equimolar solutions of the three metals, the $\mathrm{Pb}^{2+}$ metal species outcompeted both $\mathrm{Cu}^{2+}$ and $\mathrm{Zn}^{2+}$ for the sorption sites on the OrgBio and MagOrgBio at high metal concentrations, and especially the adsorption of $\mathrm{Zn}^{2+}$ was suppressed (Fig.4(d)). In equimolar solutions, the maximum sorption capacities of MagOrgBio were highest for $\mathrm{Pb}^{2+}(0.14$ moles $/ \mathrm{kg})$, lower for $\mathrm{Cu}^{2+}(0.06$ moles $/ \mathrm{kg})$, and showed a downward trend with increasing total metal concentration for $\mathrm{Zn}^{2+}$. This indicates that the three bivalent metal cations competed for the same sorption sites, with $\mathrm{Zn}^{2+}$ being the least competitive. The same trends were observed for OrgBio (see Fig.S2 in Supporting Information).

At the end of the tri-metal adsorption isotherms, the MagCocoAC was recovered with a rod magnet, dried and scanned with SEM-EDX. The distribution of all heavy metal elements were overlaid onto the pristine MagCocoAC image, and the distributive correlations of $\mathrm{Pb}, \mathrm{Cu}$ and Zn with Fe were plotted (Fig.5). From Fig.5(a), it can be seen that the iron oxides were attached to the CocoAC matrix, and no separate iron oxide particles were found. The distributions of $\mathrm{Pb}, \mathrm{Cu}$, and $\mathrm{Zn}$ correlated positively with the distribution of $\mathrm{Fe}$ (Fig.5(b),(c), and (d)), indicating at least partial association of $\mathrm{Pb}, \mathrm{Cu}$, and $\mathrm{Zn}$ with the surface of iron oxides.

\section{Conclusions}

Both activated carbons and biochars could be readily impregnated with magnetite/maghemite using wet deposition and produced sorbents with magnetic susceptibilities broadly in line with theoretical predictions for carbon-magnetite composites. The magnetization process did not significantly change the phenanthrene affinity for the activated carbon or biochar surfaces in the composites, but reduced phenol sorption. Like their pristine materials, the high surface area sorbents MagCoalAC, MagCocoAC, and MagBio had the best adsorption affinity for organic compounds. Contrarily, the lowest surface area MagOrgBio had the highest metal adsorption. The findings suggest that magnetic activated carbon or biochar composite 
materials can be custom tailored to different pollution problems by choosing the most appropriate carbonaceous matrix whose properties are largely preserved during magnetization. Especially the two biochars had very distinct sorption properties, and the high surface area biochar nearly reached the very strong organic pollutant binding capacity of the activated carbons. Magnetic biochars should therefore be further explored for environmental remediation applications, as they may provide a more sustainable sorbent alternative to coalderived magnetic activated carbons. While the composite materials often showed a fairly broad pollutant binding capacity for different organic and inorganic pollutants, reduced adsorption of individual species from a multi-pollutant mixture due to competitive adsorption, as well as the $\mathrm{pH}$ dependency of sorption, also has to be taken into account when designing practical applications in dirty matrices. Further work needs to explore the regeneration and reuse of the magnetic sorbent materials, which may reduce the cost of their use in environmental remediation.

\section{Acknowledgments}

Zhantao Han was supported by the China Scholarship Council, a grant of the Royal Academy of Engineering (1314RECI002) and a grant of China Geological Survey (12120113102700). Badruddeen Sani was supported by the Nigerian Petroleum Technology Development Fund.

\section{Supporting Information}

Methods for the magnetic activated carbon/biochar synthesis and determination of sorption isotherm parameters, results of phenol sorption isotherm parameters, bivalent metal cation sorption isotherm parameters, and $\mathrm{pH}$ data for phenol and bivalent cations adsorption were provided in supporting information.

\section{References}


devices: Passive samplers for measuring dissolved hydrophobic organic compounds in aquatic environments.

Environmental Science \& Technology 41 (4), 1317-1323.

Ahn, S., Werner, D., Karapanagioti, H., McGlothlin, D. R., Zare, R. N. and Luthy, R. G. (2005) Phenanthrene and pyrene sorption and intraparticle diffusion in polyoxymethylene, coke, and activated carbon. Environ. Sci.

Borah, D., Satokawa, S., Kato, S. and Kojima, T. (2009) Sorption of As(V) from aqueous solution using acid modified carbon black. Journal of Hazardous Materials 162 (2-3), 1269-1277.

Carter, M. C., Kilduff, J. E. and Weber, W. J. (1995) Site Energy Distribution Analysis of Preloaded Adsorbents. Environmental Science \& Technology 29 (7), 1773-1780.

$164(2-3), 609-614$.

Chen, B., Chen, Z. and Lv, S. (2011) A novel magnetic biochar efficiently sorbs organic pollutants and phosphate. Bioresource Technology 102 (2), 716-723.

Cheremisinoff , N. P. (2002) Handbook of air pollution prevention and control Amsterdam: Butterworth-

Heinemann.

Cho, Y.-M., Werner, D., Choi, Y. and Luthy, R. G. (2012) Long-term monitoring and modeling of the mass

transfer of polychlorinated biphenyls in sediment following pilot-scale in-situ amendment with activated carbon.

447 Choi, Y., Cho, Y.-M. and Luthy, R. G. (2013) Polyethylene-Water Partitioning Coefficients for Parent- and 448 Alkylated-Polycyclic Aromatic Hydrocarbons and Polychlorinated Biphenyls. Environmental Science \& 
activated carbon—a critical review. Chemosphere 58 (8), 1049-1070.

Faulconer, E. K., von Reitzenstein, N. V. H. and Mazyck, D. W. (2012) Optimization of magnetic powdered activated carbon for aqueous $\mathrm{Hg}(\mathrm{II})$ removal and magnetic recovery. Journal of Hazardous Materials 199 9-14. 1168.

Hale, S. E. and Werner, D. (2010) Modeling the mass transfer of hydrophobic organic pollutants in briefly and (2012a) Activated carbon amendment to sequester PAHs in contaminated soil: A lysimeter field trial.

Hale, S. E., Hanley, K., Lehmann, J., Zimmerman, A. R. and Cornelissen, G. (2012b) Effects of Chemical,

Biochar. Environmental Science \& Technology 46 (4), 2479-2480. properties of $\mathrm{Fe} 3 \mathrm{O} 4$-activated carbon magnetic nanoparticles for removal of aniline from aqueous solution: equilibrium, kinetic and thermodynamic studies. Iranian Journal of Environmental Health Science \& Engineering 10

Kim, W., Suh, C.-Y., Cho, S.-W., Roh, K.-M., Kwon, H., Song, K. and Shon, I.-J. (2012) A new method for the identification and quantification of magnetite-maghemite mixture using conventional X-ray diffraction 
Langmuir, I. (1916) The constitution and fundamental properties of solids and liquids. J. Amer. Chem. Soc. 38 2221-2295.

Lucas, I. T., Durand-Vidal, S., Dubois, E., Chevalet, J. and Turq, P. (2007) Surface Charge Density of Maghemite Nanoparticles: Role of Electrostatics in the Proton Exchange. The Journal of Physical Chemistry C 111 (50), 18568-18576.

Milonjić, S. K., Kopečni, M. M. and Ilić, Z. E. (1983) The point of zero charge and adsorption properties of natural magnetite. Journal of Radioanalytical Chemistry 78 (1), 15-24.

Mohan, D., Sarswat, A., Singh, V. K., Alexandre-Franco, M. and Pittman Jr, C. U. (2011) Development of magnetic activated carbon from almond shells for trinitrophenol removal from water. Chemical Engineering Journal 172 (2-3), 1111-1125.

Ngarmkam, W., Sirisathitkul, C. and Phalakornkule, C. (2011) Magnetic composite prepared from palm shellbased carbon and application for recovery of residual oil from POME. Journal of Environmental Management 92 (3), 472-479.

Oliveira, L. C. A., Rios, R. V. R. A., Fabris, J. D., Garg, V., Sapag, K. and Lago, R. M. (2002) Activated carbon/iron oxide magnetic composites for the adsorption of contaminants in water. Carbon 40 (12), 2177-2183.

Redlich, O. and Peterson, D. L. (1959) A useful adsorption isotherm. J. Phys. Chem. 63 (6), 1024-1024.

Reymond, J. P. and Kolenda, F. (1999) Estimation of the point of zero charge of simple and mixed oxides by mass titration. Powder Technology 103 (1), 30-36.

Rossier, M., Koehler, F. M., Athanassiou, E. K., Grass, R. N., Aeschlimann, B., Gunther, D. and Stark, W. J. (2009) Gold adsorption on the carbon surface of C/Co nanoparticles allows magnetic extraction from extremely diluted aqueous solutions. Journal of Materials Chemistry 19 (43), 8239-8243.

Shen, J., Ebner, A. D. and Ritter, J. A. (1999) Points of Zero Charge and Intrinsic Equilibrium Constants of Silica-Magnetite Composite Oxides. Journal of Colloid and Interface Science 214 (2), 333-343. 
DVGW-Forschungsstelle. 722.

Sparrevik, M., Saloranta, T., Cornelissen, G., Eek, E., Fet, A. M., Breedveld, G. D. and Linkov, I. (2011) Use of

Life Cycle Assessments To Evaluate the Environmental Footprint of Contaminated Sediment Remediation.

Environmental Science \& Technology 45 (10), 4235-4241.

Takeno, N. (2005) Atlas of Eh-pH diagrams-intercomparison of thermodynamic databases.

Walters, R. W. and Luthy, R. G. (1984) Equilibrium adsorption of polycyclic aromatic hydrocarbons from water

Wang, X. S., Zhu, L. and Lu, H. J. (2011) Surface chemical properties and adsorption of Cu (II) on nanoscale magnetite in aqueous solutions. Desalination 276 (1-3), 154-160.

Wang, Y.-H., Lin, S.-H. and Juang, R.-S. (2003) Removal of heavy metal ions from aqueous solutions using various low-cost adsorbents. Journal of Hazardous Materials 102 (2-3), 291-302. nanocomposite particles for dye removal. Materials Letters 62 (4-5), 645-647. 
sorbents to reduce PCB and PAH bioavailability in marine sediments. Physicochemical tests. Environ. Sci.

521 Technol. $38(20)$, 5458-5464.

522

523

524 


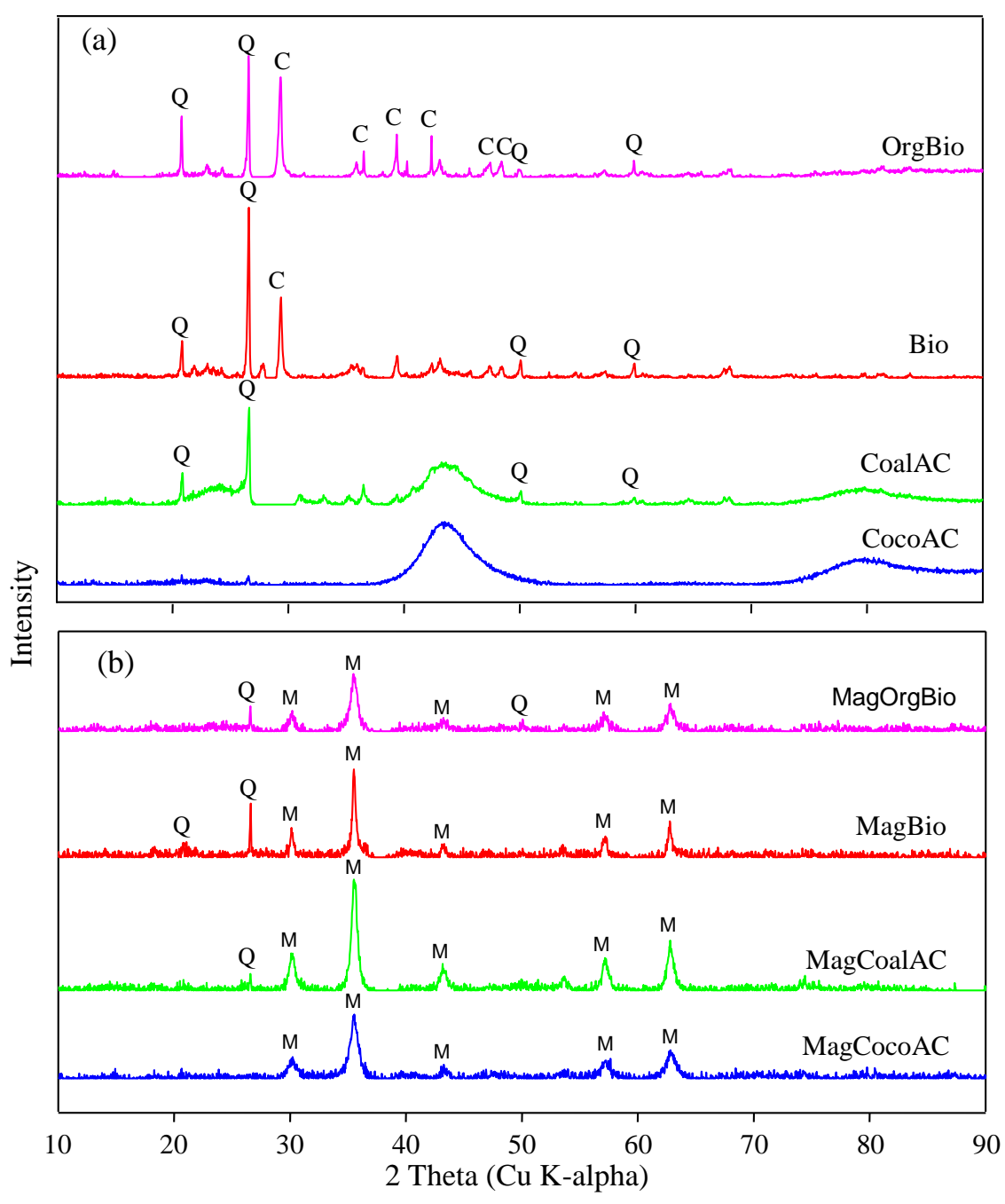

Fig.1-XRD patterns of (a) pristine carbon; (b) magnetic carbon.

M: Magnetite or Maghemite; C: Calcite; Q: Quartz. 


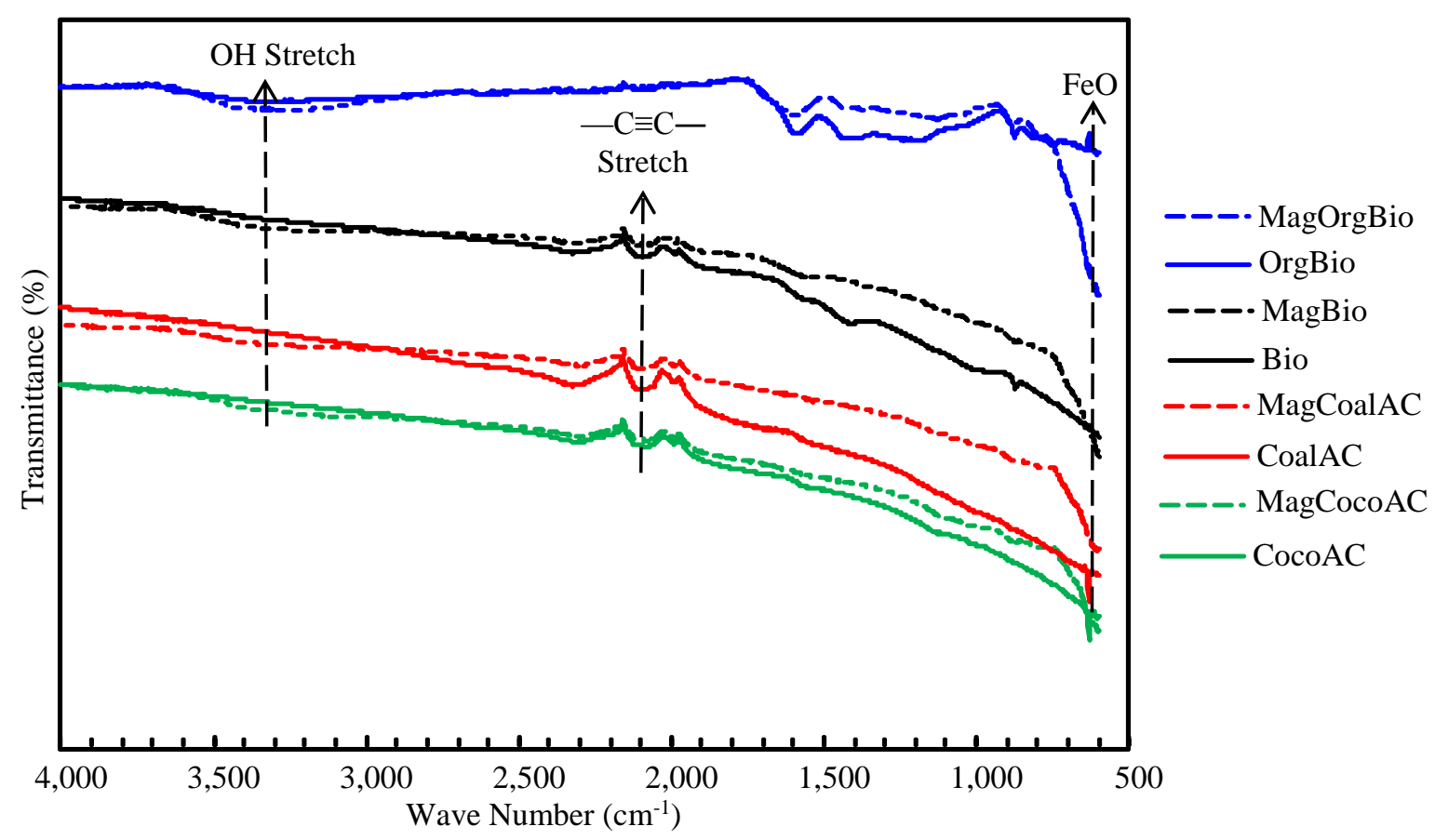

Fig.2-FTIR spectrum of AC, biochar, MAC, and MBC.
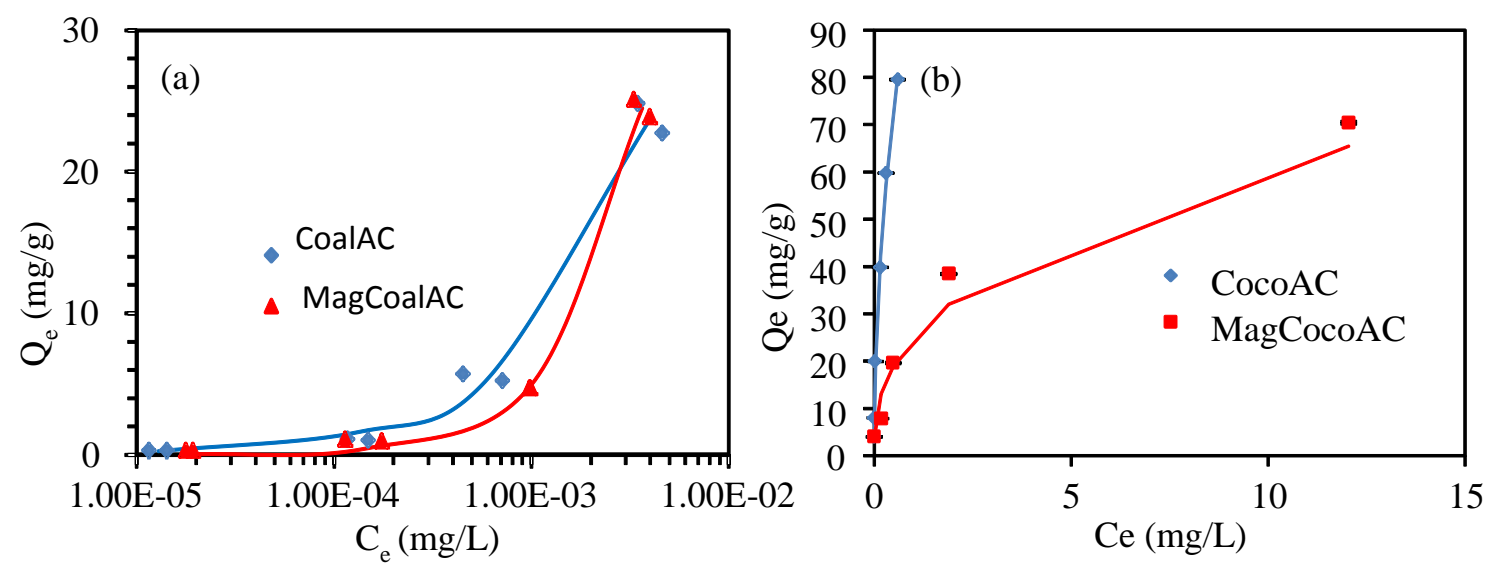

Fig. 3- Comparison of sorption isotherms for (a) phenanthrene and (b) phenol on selected sorbents. Solid lines are fitted by the Freundlich model. 


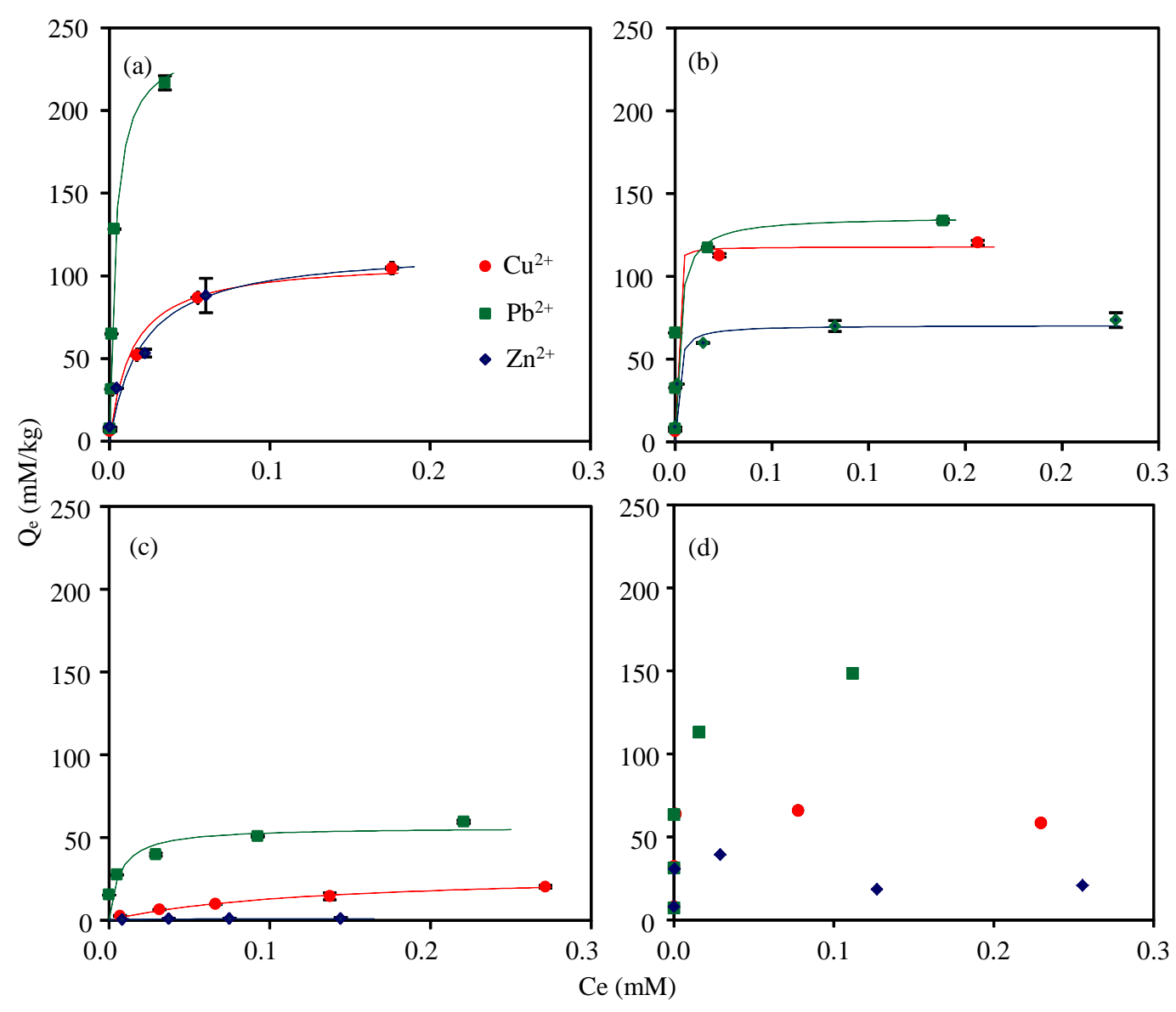

Fig.4-Sorption of individual metals on (a) OrgBio*, (b) MagOrgBio*, (c) Magnetite* with fitted Langmuir isotherms and (d) MagOrgBio sorption data of the same metals in combination from equimolar solution.

*Solid lines fitted by Langmuir model 